\title{
Performance Evaluation of Yield Monitoring System for Rice Combine Harvester in Selangor, Malaysia
}

\author{
Renny Eka Putri", Azmi Yahya ${ }^{* 1}$, Nor Maria Adam ${ }^{+}$and Samsuzana Abd Aziz ${ }^{* 2}$ \\ \# Department of Agricultural Engineering, Faculty Agricultural Technology, University Andalas, West Sumatera, Indonesia \\ E-mail: renny.ekaputri@yahoo.co.id
}

*Department of Biological and Agricultural Engineering, Faculty Engineering, University Putra Malaysia, 43400, Selangor, Malaysia E-mail: ${ }^{1}$ azmiy@eng.upm.edu.my; ${ }^{2}$ samsuzana@upm.edu.my

\author{
${ }^{+}$Department of Mechanical Engineering, Faculty Engineering, University Putra Malaysia, 43400, Selangor, Malaysia \\ E-mail: mariah@upm.edu.my
}

\begin{abstract}
Yield monitoring system constructed for combine harvester was able to monitor and store required, measured attributes during field tests. A rugged, wireless crop yield monitoring instrumentation system was employed on a rice combine harvester to measure instantaneous rice yield in this study. A mild steel chute mounted with SWR SolidFlow microwave type flow sensor and SWR M-Sens 2 microwave type moisture sensor were located at the end top of the clean grain auger of the combine harvester to the flow rate of the dropped grain into the grain storage tank and measure the moisture content of the grain transferred by the auger. The objective of conducted performance test was to check both the operational and robustness of the instrumentation system under the actual harvesting operation with the combine in the paddy field. During harvesting, the embedded system, DGPS, router and all sensors within the instrumentation system functioned reliable. Instrumentation system records combined multiple data by following moisture content $(\%)$, cutting width $(\mathrm{mm})$, elevator rotation speed (RPM) and combine speed (km/hr). Through yield monitoring and yield mapping, the rice farmers could correct soil nutrient defiencies as indicated by the yield variabilities within the plot for the next cropping season.
\end{abstract}

Keywords - Yield Monitoring; Field Performance; Rice Combine Harvester.

\section{INTRODUCTION}

A yield monitor system is installed on the combine harvester so that crop yield data can be collected automatically during the harvesting operation. Yield monitoring makes it possible to provide farmers a new information management tools to optimize the crop inputs and outputs, and better manage their farm operations [1]. By means of yield monitoring and mapping, farmers will investigate option for reducing the production cost while increasing crop yield. Using this technology, farmer will developed proficiency with chemicals and fertilizer application at the right amount, right time and right locations in the field. Farmers will realize the potential of greater profitability with lower input costs, and identification of poor producing areas of their fields.

Development and practical use of yield monitoring in grain combine harvesters has been conducted throughout the years [2-8]. The yield monitoring system was used during harvesting operation to determine the yield variability within the harvested paddy area. In yield monitoring, measurements of instantaneous flow of collected clean grain at the grain tank was collected and then plotted against spatial coordinate to generate a crop yield map. Relating the yield map with other input maps may reveal the root causes of low yield at the relevant location with the paddy. Variability of yield is quantified by the yield map to explain the reasons why certain areas only produce a low yield. Following from these analysis actions could be taken within critical regions of the paddy to improve yield for the upcoming crop cropping seasons.

$\mathrm{Ju}$ [9] developed a simple, portable and rugged instrumentation system that could be directly used on any rice combine harvester from different makes and models to monitor, measure and record in real-time the harvested crop yield. The basis of the technology, a microwave solid flow sensor was used in place of the more common force-impetus 
sensor. In the study, a mild steel chute mounted with SWR SolidFlow microwave type flow sensor and SWR M-Sen 2 microwave moisture sensor were positioned at the end of the clean grain auger measure to the mass flow rate and moisture content of the grain transferred by the auger into the grain tank. The objective of performance test was to check the operational of yield monitoring system under the actual harvesting operation with the combine in the paddy field.

\section{MATERIALS AND METHODS}

The main components of instrumentation system for measuring and monitoring travel speed, cutting width, elevator speed, grain flow, grain moisture, and the geospatial position of the combine harvester (Fig. 1 and 2). The detail function of the related components of the instrumentation system is summarized in Table 1.

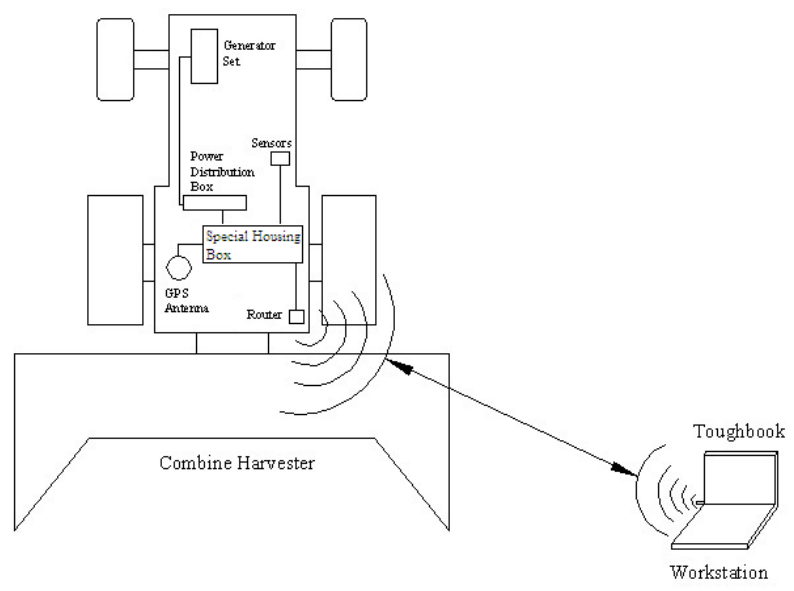

Fig 1. Schematic diagram of the complete instrumentation system [10].

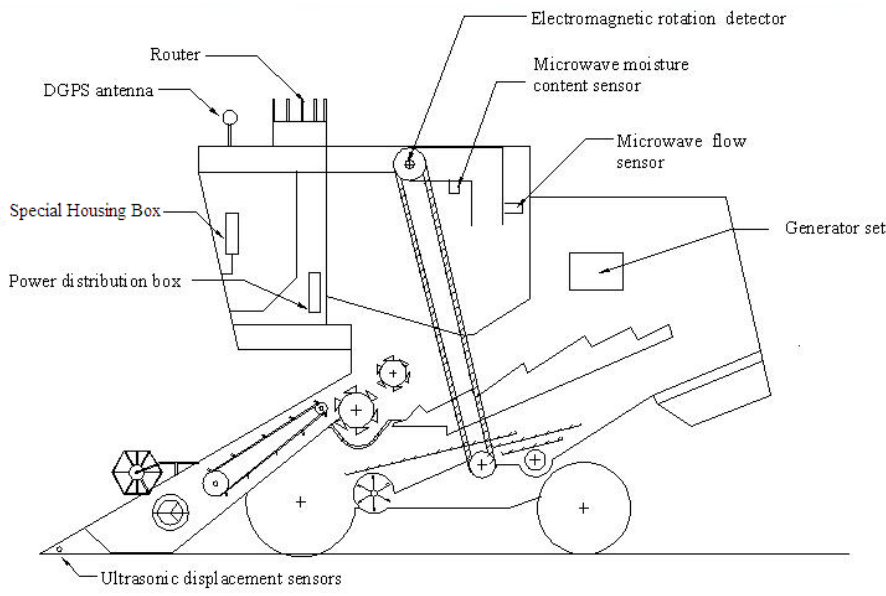

Fig 2. Combine harvester with instrumentation system [10].

A special housing was constructed to contain the National Instrument CompactRio 9004 embedded system with NI 9221 I/O module, National Instrument 2016 touch panel component (TPC), Trimble AgGPS 132 DGPS receiver and two evaluation units for the SWR Solid flow sensor and SWR M-Sens 2 moisture sensor. The latitude and longitude position of each sampling point was recorded using a Trimble AgGPS 132 DGPS. The differential correction process was done automatically in real time using available beacon reference station at Lumut $(4015.075 " \mathrm{~N}$ and 100039.638"E), and Perak (transmission frequency was $298.00 \mathrm{kHz}$ ). The location of latitude and longitude (WGS84) were next converted to Malaysia Rectified Skew Orthomorphic (RSO) using GPS Pathfinder Office 2.90. The yield data in Excel format were then transferred through a thumb drive to ArcGIS 10.1 with spatial analyst extension to generate krigged spatial map. This housing was located in close proximity machine operation to the enclosure. The Dlink DIR-655 router with 3 D-link ANT24-0700 antennas and Trimble AgGPS 132 DGPS antenna were fixed on the operator enclosure roof using special magnetic supports. A honda EU20i generator set was fixed at the rear left side of combine harvester, while the power distribution box was located behind the driver seat in the operator enclosure so that it was close vicinity to the special system housing. The two units of Omron EP4A-LS200-M1-N ultrasonic displacement sensors were located at each side of the combine header to measure actual cutting width of combine. The ONO SOKKI MP-810 shaft speed sensor electromagnetic rotation detector was directed coupled to the drive shaft of the grain elevator unit of the combine.

The SWR M-Sens 2 microwave type moisture sensor was located at the grain leveling auger at the top of the combine grain elevator while the SWR Solid flow microwave type flow sensor was mounted to the elbow chute located at the end of the grain leveling auger. Data from the embedded system were wirelessly transferred through the router to the adaptor on the toughbook at the on-ground workstation. All the measured data the embedded system was displayed online on the TPC for combine operator. The system used a portable generator set for a power supply. Concurrently, data received by the toughbook displayed the operator at the onground workstation and subsequently stored to hard drive.

TABLE 1.

DETAIL COMPONENTS OF THE INSTRUMENTATION SYSTEM AND THEIR RESPECTIVE FUNCTIONS.

\begin{tabular}{|c|c|}
\hline Name of Component & Function \\
\hline $\begin{array}{l}\text { National Instrument CompactRio } \\
9004 \text { embedded system with NI } \\
9221 \text { I/O module }\end{array}$ & $\begin{array}{l}\text { Controls for acquiring, conditioning, } \\
\text { amplifying, and processing sensor } \\
\text { signals and DGPS receiver output }\end{array}$ \\
\hline National Instrument 2016 TPC & $\begin{array}{l}\text { Displays the measured data to the } \\
\text { combine operator. }\end{array}$ \\
\hline $\begin{array}{l}\text { Panasonic CF-19 toughbook with } \\
\text { in-house National Instrument } \\
\text { LabVIEW } 8.6 \text { software }\end{array}$ & $\begin{array}{l}\text { Controls for receiving, displaying } \\
\text { and saving the measured data. }\end{array}$ \\
\hline $\begin{array}{l}\text { D-link DIR-655 router with } 3 \text { D- } \\
\text { link ANT24-0700 antennas and a } \\
\text { D-link DWA-140 USB adapter }\end{array}$ & $\begin{array}{l}\text { Provides wireless communication } \\
\text { between the embedded system and } \\
\text { the toughbook. }\end{array}$ \\
\hline Trimble AgGPS 132 DGPS & $\begin{array}{l}\text { Measures geospatial position of the } \\
\text { combine harvester in the field. }\end{array}$ \\
\hline $\begin{array}{l}\text { Omron EP4A-LS200-M1-N } \\
\text { ultrasonic displacement sensors }\end{array}$ & $\begin{array}{l}\text { Measures the harvested cutting width } \\
\text { of the combine. }\end{array}$ \\
\hline $\begin{array}{l}\text { ONO SOKKI MP- } 810 \\
\text { electromagnetic rotation detector }\end{array}$ & $\begin{array}{l}\text { Measures the rotational speed of the } \\
\text { combine grain elevator }\end{array}$ \\
\hline $\begin{array}{l}\text { SWR M-Sens } 2 \text { microwave type } \\
\text { moisture sensor and evaluation } \\
\text { unit }\end{array}$ & $\begin{array}{l}\text { Measures the moisture content of } \\
\text { clean grain going into the grain tank. }\end{array}$ \\
\hline $\begin{array}{l}\text { SWR SolidFlow microwave type } \\
\text { flow sensor and evaluation unit }\end{array}$ & $\begin{array}{l}\text { Measures the flow of clean grain } \\
\text { dropping into the grain tank. }\end{array}$ \\
\hline $\begin{array}{l}\text { HONDA EU20i generator set } \\
\text { with the power distribution box } \\
\text { on board }\end{array}$ & $\begin{array}{l}\text { Provides the input power to run the } \\
\text { system. }\end{array}$ \\
\hline
\end{tabular}

Source: A. Yahya, et al (2012) 
Both the TPC on the housing and the toughbook monitor were programmed to display the universal time coordinated (UTC) time, local time, latitude, north/south (N/S) indicator, longitude, east/west (E/W) indicator, position fix, satellites used, horizontal dilution of precision (HDOP), altitude, DGPS station ID and checksum of DGPS system, left crop position distance, right crop position distance, combine cutting width, grain flow, instantaneous crop yield, total grain, combine elevator rotational speed, grain moisture content and combine travel speed. Data were safe to the Toughbook hard drive in ASCII format.

This study was conducted in the rice fields at Blok E5 Parit Timur 5 of Sungai Besar, Selangor at latitude 3o 41' 30.187" N and longitude 1010 01' 41.877" E location. The rice area is located on a flat coastal plain under the Integrated Agricultural Development Authority (IADA) Rice Granary within the district of Kuala Selangor and Sabak Bernam. The district of Sungai Besar is well known as one of the main rice growing area in Malaysia. Three rice plots with an individual size of 1.09 ha were randomly selected from the 40 available rice plots within the Parit 5 rice area of Sungei Besar. Field observations and data collection on the selected rice plots were done in two consecutive rice growing seasons.

\section{RESULTS AND DISCUSSION}

The yield monitoring instrumentation system constructed for combine harvester was able to monitor and store required, measured attributes during field tests. During harvesting, the embedded system, DGPS, router and all sensors within the instrumentation system functioned reliable. During the harvesting process, instrumentation system records combined multiple data by following cutting width $(\mathrm{mm})$, elevator rotation speed (RPM) and combine speed $(\mathrm{km} / \mathrm{hr})$.

\section{A. Instantaneous Yield}

The instantaneous yield by the instrumentation system onboard the combine was recorded in ton per hectare. The tonnage rate was calculated from flow rate sensor in kilograms per hour and the area of cut in $\mathrm{m}^{2}$ which was calculated from the cutting width in meter multiplied by the travelled speed of the combine. Although using same seeds, uniform fertilizer application and pest control system were used within each lot, yield variability within the rice plot. It is possible as mentioned by Blackmore [11] as he stated that this might be caused by two factors which are permanent features and variable features. The permanent features of the field include soil type, topography, streams, and high trees. The variable features include ununiformed distribution of seed, fertilizer application, and pest control.

Harvested rice yield from instrumentation system for the rice plots were interpolated using kriging implementation of Arc GIS 10.1. The purpose of interpolation was to produce a surface coverage or spatial distribution of the yield parameter. ESRI [12] introduced a classification technique of smart quartiles. This method was selected through visualized variability based on the natural grouping of data values. The entire yield map was divided into five zone areas of yield. The kriged maps were able to show the variations in yield within each individual field plots, and at the same time able to indicate which locations within the field plots had low yields. These maps will become important management tool for remedial agronomic actions to improve crop yield during the following growing season.

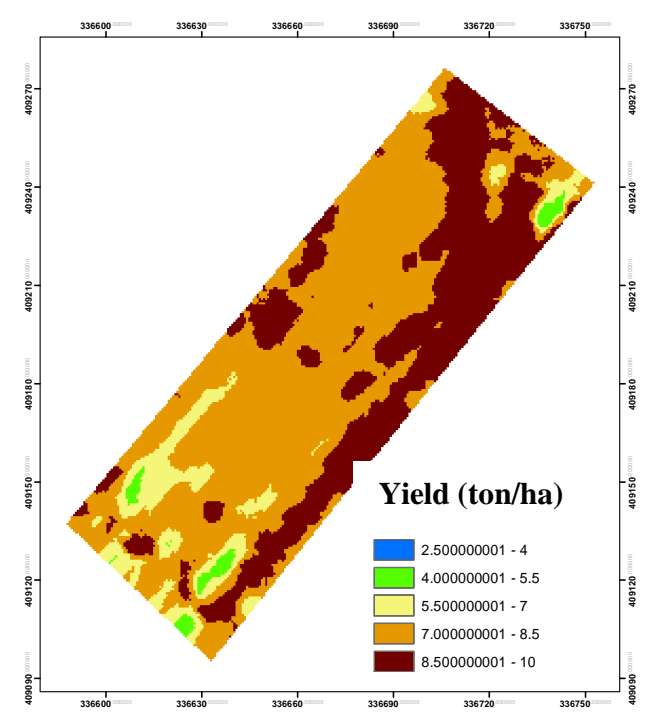

Fig 3. Kriged yield maps (ton/ha)

\section{B. Instantaneous Moisture Content}

The SWR M-Sens 2 microwave type moisture sensor was used to determine the instantaneous moisture content during harvest operations. The most dominant distribution of the instantaneous moisture content was the high moisture content range of 24 to $26 \%$ which covered $26.41 \%$ and $44.70 \%$ of the total area in first and second growing season, respectively. Figure 4 show the kriged map of moisture content distribution in paddy plot.

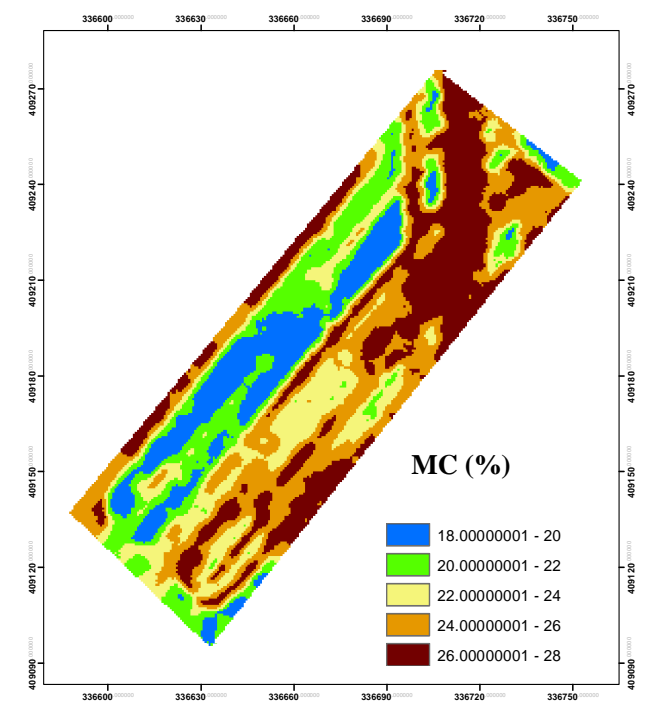

Fig 4. Kriged moisture content maps (\%)

\section{Combine Track}

The combine harvester was operated in circuitous round corner patterns around field border followed by the headland pattern from boundaries to finish harvesting of the middle area for all plots (figure 5). 


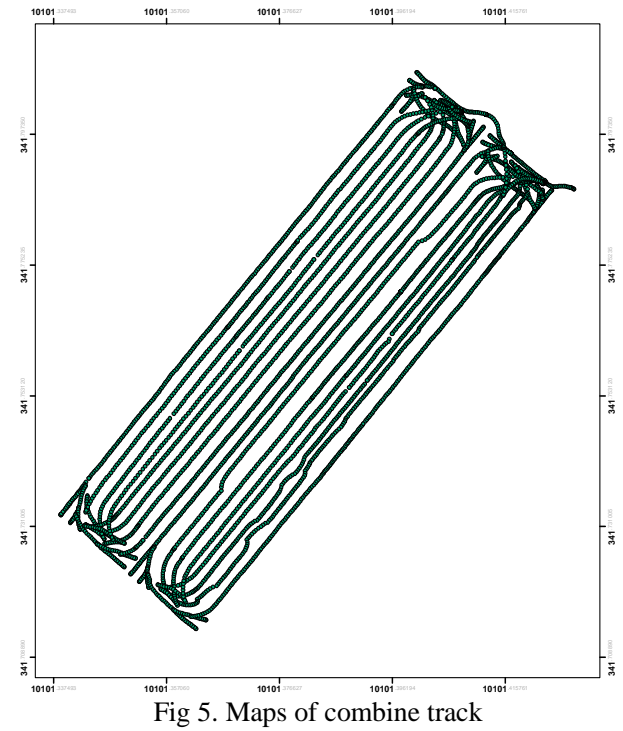

\section{Cutting Width}

The combine harvester was consistently operated at the maximum cutting width ranging from 3601 to $4000 \mathrm{~mm}$. As shown in the plot maps, the combine harvester was operated at a greater cutting width at the beginning of the harvesting operation especially along the sub plot side length boundary and at the lower cutting width as the combine harvester began harvesting in a headland pattern. Figure 6 show combine cutting width maps of associated paddy lots.

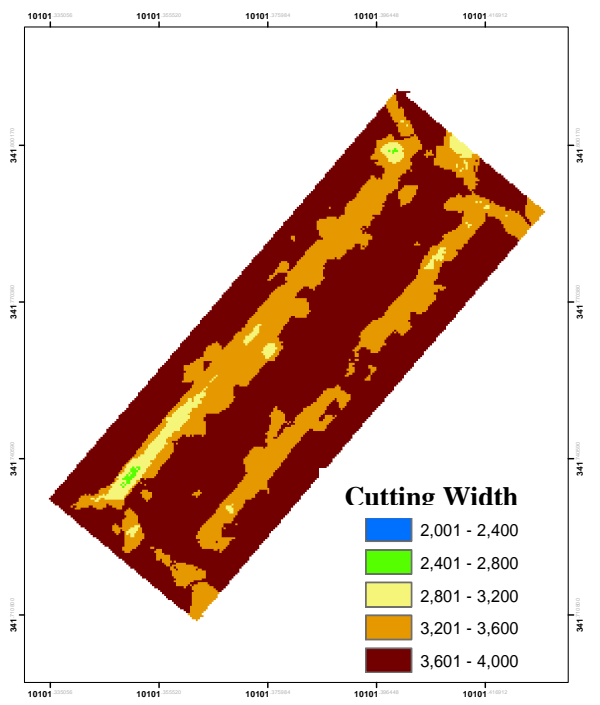

Fig 6. Kriged maps cutting width (mm)

\section{E. Elevator Speed}

Combine elevator speed map is displayed in Figure 7, as shown in krigged maps that associated rice plot have dominant high combine elevator speed range of 230 to 240 rpm which covered up to $86.11 \%$ of the total area for both growing season (figure 7).

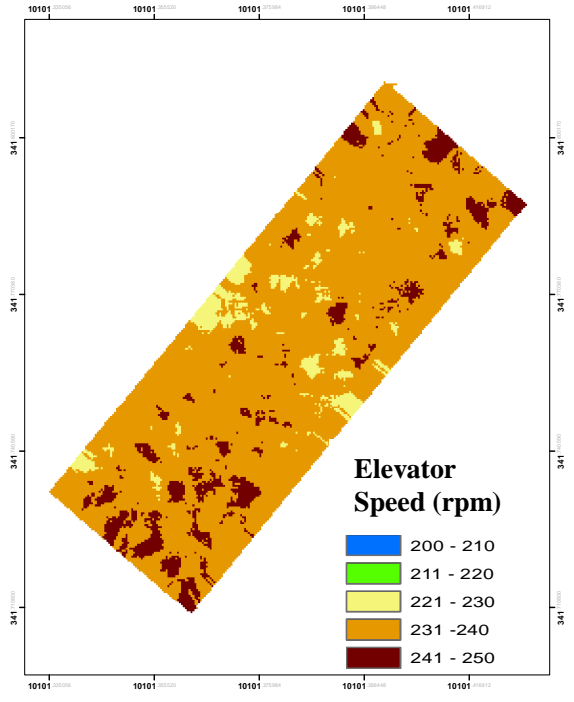

Fig 7. Kriged maps elevator speed (rpm)

\section{F. Combine Speed}

The most dominant combine speed of associated plots was moderate speed range of 2.6 to $3.4 \mathrm{~km} / \mathrm{hr}$ which covered up to $71.61 \%$ of the total area (figure 8 ). The combine harvester unloaded periodically into the lorry for transport of the grain to the collection point.

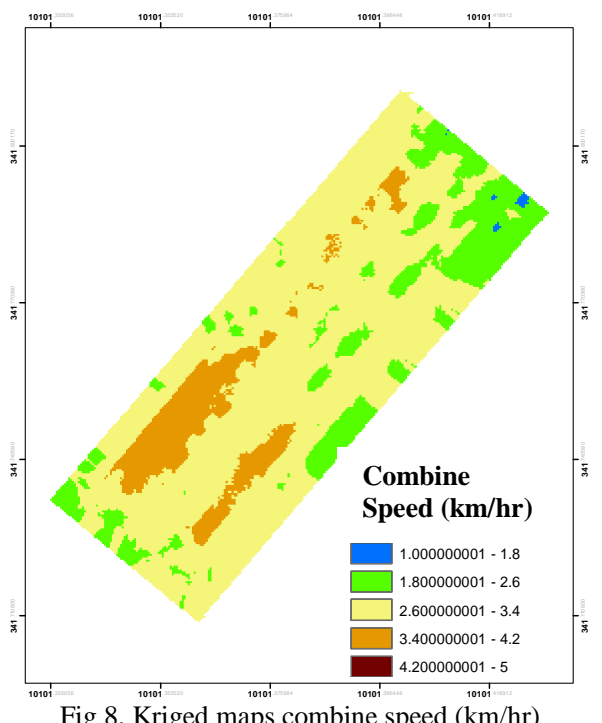

\section{CONCLUSIONS}

In conclusion, the field test on the yield monitoring system has been successfully to monitor harvested crop yield and combine operating parameters. The results have showed that all the sensors on the instrumentation system were able to measure, display and record all the parameters using the instrumentation system during the harvesting operation. The instantaneous crop yield plotted maps were able to show the variations in instantaneous crop within each individual field plots and at the same time able to indicate which area locations within the individual field plots having low yields for any possible remedial in-situ agronomic actions to be taken to improve the crop yield of the field plot for the next coming growing season. 


\section{REFERENCES}

[1] Doerge, T. (1999). Yield monitoring create on and off farm profit opportunity. Crop Insights, Pioneer Hybrid International. 9(14):1-4

[2] Arslan, S., and T. S. Colvin. (1998). Laboratory test sand for combine grain yield monitors. Applied Eng. Agric. 14(4): 369-371.

[3] Arslan, S., and T. S. Colvin. (1999). Laboratory performance of a yield monitor. Applied Eng. Agric. 15(3): 189-195.

[4] Arslan, S. and T. S. Colvin. (2002a). An evaluation of the response of yield monitors and combines to varying yields. Precision Agriculture, 3:107-122.

[5] Al-Mahasneh, M. A., Colvin, T. S. (2000). Verification of yield monitors performance for on-the-go measurement of yield with an inboard electronic scale. Trans. of the ASAE 34(4): 801-807.

[6] Chosa, T., Shibata, Y. and Omine, M. (2002). A study on yield monitoring system for head-feeding combines. I. Adoption of an Optical Sensor and a Load Cell as a Yield Monitor. Journal Japan Society Agricultural Machanization 64(6): 145-153.
[7] Chosa, T., Shibata, Y., Kobayashi, K., Daikoku, M., Omine, M., Toriyama, K., and Hosokawa, H. (2006). Yield monitoring system for a head-feeding combine. Japan Agricultural Research Quarterly 40(1): 37-39.

[8] Shoji, K., Kawamura, T. and Horio, H. (2005). Variability of MicroElevation, Yield, and Protein Content within a Transplanted Paddy Field. Faculty of Agriculture, Kobe University, Kobe 657-8501, Japan.

[9] Ju., O. Y. (2011). Development of a portable, real-time, wireless crop yield monitoring system on rice combine. Publish by Mater Thesis. University Putera Malaysia.

[10] Yahya, M. M. Isa, and S. Abd. Aziz. (2012). Portable Wireless Yield Monitoring System for Rice Combine. Paper Presenter at the International Conference on "Agricultural and Food Engineering for Life", Putrajaya.

[11] Blackmore, B. S., and Larscheid, G. (2003). Strategies for managing variability. The role of yield maps in Precision Farming.

[12] ESRI. (2001). Using ArcGIS; Geostatistical Analyst. ESRI, CA. 